\title{
Role Conflict and Role Ambiguity in Pediatric General Duty and Intensive Care Unit Nurses
}

\author{
Deniz Şanlı' $\mathbb{D}$, Meryem Ünal Çimen² ${ }^{2}$, Nurseren Işler ${ }^{2}$, Nuriye Turgut ${ }^{2}$ (D) \\ 'Department of Surgical Nursing, İzmir Katip Çelebi University Faculty of Health Sciences, İzmir, Turkey \\ ${ }^{2}$ Pediatric Intensive Care Unit, University of Health Sciences Dr. Behçet Uz Child Disease and Pediatric Surgery Training and Research \\ Hospital, İzmir, Turkey
}

ORCID iDs of the authors: D.Ş. 0000-000I-6076-03I7; M.Ü.Ç. 0000-0003-3375-765I; N.I. 0000-0002-4506-9373; N.T. 0000-0002-0286$174 X$.

Cite this article as: Şanlı D, Çimen MÜ, İşler N, Turgut N. Role Conflict and Role Ambiguity in Pediatric General Duty and Intensive Care Unit Nurses. Cyprus J Med Sci 2021; 6(2): 162-170.

\section{BACKGROUND/AIMS}

The aim of this study is to investigate the role conflict and role ambiguity in pediatric nurses who work outside and in the pediatric intensive care units and whether the situation varies according to some characteristics of the nurses.

\section{MATERIAL and METHODS}

The descriptive study was carried out in intensive care units with featured units, other featured units (emergency service, operating room, and burn unit), and inpatient clinics in a pediatric hospital between October l, 2019 and February l, 2020. All nurses were included in the sample using the total count sampling method $(\mathrm{N}=210)$. The data were collected using a Nurse Personal Information Form and the Role Conflict and Role Ambiguity Scale.

\section{RESULTS}

The mean role conflict score of the nurses who worked in the hospital was $35.74 \pm 9.34$ and above the moderate level, while the mean role ambiguity score was $39.90 \pm 5.71$ and they experienced no role ambiguity. The mean role conflict score of the nurses in the clinic $(37.38 \pm 9.46)$ was significantly higher than those in the intensive care unit $(33.80 \pm 9.15)(F=3.42, P=.03)$. The role conflict was higher in nurses who spent more years in the profession, in the hospital, and have not received orientation training in the hospital, whereas the role ambiguity was higher in nurses who have not received orientation training in the hospital $(P<.05)$.

\section{CONCLUSION}

The working environments in health institutions create a favorable ground for role conflict and role ambiguity.

Keywords: Pediatric nursing, critical care nursing, intensive care unit, role conflict, role ambiguity

\section{INTRODUCTION}

Nursing in our country has experienced a swift transformation in recent years and has turned into an autonomous profession with the developments regarding its qualifications and competence.' Nursing is legally defined as a profession that requires an undergraduate degree, ${ }^{2}$ and its duties, authorities, and responsibilities are explained according to the unit worked in. ${ }^{3}$ The development of medical science and the changes in health needs have also affected the roles in nursing.' Different demands are made on the nurses in different working environments. When the tasks in the acute and long-term care institutions are not clearly defined, the working environment can be stressful. ${ }^{4}$ Intensive care unit (ICU) is a complex and challenging environment. When physicians hold the authority, ICU nurses may not work with clear roles and responsibilities. ${ }^{5}$ The development of new roles in ICU nursing is a response to the advances in health technology. Many nurses face problems of role conflict, role ambiguity, excessive workload, ambiguity of role boundaries, and autonomy. ${ }^{6}$

Health institutions are environments that are open to conflict, since they bring together different employees. One of the most commonly defined sources of conflict is role conflict and role ambiguity. Status-related barriers among healthcare 
workers are one of the communication barriers. ${ }^{8}$ Hierarchy, interpersonal differences of power, role conflict, and role ambiguity cause erroneous communication between nurse and physician. ${ }^{9}$ According to Weiss et al., ${ }^{4}$ role conflict, lack of a clear job description, and inability to adapt to the job are the causes of stress in the work environment.

Role conflict is incompatible role expectations and may occur among and within roles. ${ }^{10,11}$ Conflicting instructions and demands of physicians, nursing managers, and head nurses cause role conflicts. ${ }^{10}$ The literature holds studies with different results showing that nurses do not have any role conflicts ${ }^{12}$ or have conflicts at various levels, ranging from middle to high. ${ }^{13-22}$ Intensive care nurses have been reported to have a moderate level of living ${ }^{5}$ and live longer than other nurses. ${ }^{10}$ Role ambiguity is a lack of information about the expected role behavior. There is an inadequate understanding of what the job is about because of the unclear job definition. ${ }^{10,23}$ The literature holds studies with different results, showing that nurses do not have any role conflicts ${ }^{12}$ or have conflicts at various levels, ranging from middle to high. ${ }^{13-22}$ It has been shown that the level in intensive care nurses is middle ${ }^{5}$ and higher than other nurses. ${ }^{10}$

Role conflict and role ambiguity have been shown to increase work-related tension, ${ }^{12}$ burnout, ${ }^{10,16,20,22}$ unethical behavior, ${ }^{23}$ staff turnover, ${ }^{13}$ and intention to leave work, ${ }^{18}$ and decrease self-efficacy, ${ }_{1}^{10}$ job performance, ${ }^{19}$ job satisfaction, 14,17,19 dedication to work, ${ }^{15}$ and organizational commitment. ${ }^{16}$ In the study of Roch et al., ${ }^{24}$ it was determined that it affected care practices. In qualitative studies, it was stated that it was among the causes of in-team conflict perceived by the nurses," resulting in the transfer of care practices to the auxiliary personnel. ${ }^{24}$

Collaboration, coordination, and compliance and clarity in role expectations are considered necessary for the fulfillment of care practices by nurses. ${ }^{24}$ Pediatric ICU is a unit where complex treatment plans of critical patients are coordinated with more than one member. Perfection in a pediatric ICU is achieved through a combination of many factors and is dependent on a healthy work environment. ${ }^{25}$ Given that the role conflict and role ambiguity results in many unfavorable sitvations for nurses, and that this is reflected in the quality of care; the importance of the studies for determining the level of the conflict and ambiguity becomes apparent. In national and international literature, no study investigating the role conflict

\section{Main Points}

- We observed that pediatric nurses had a moderate level of role conflict and no role ambiguity.

- We demonstrated that nurses working in the clinic experienced more role conflicts than nurses working in the ICU.

- We found that nurses working in the intensive care and in the hospital, nurses who spent more years in the hospital and in the profession, and nurses who have not received orientation training from the hospital experienced more role conflicts.

- We also found that pediatric nurses who have not received orientation training in the hospital experienced more role ambiguity. and role ambiguity in pediatric nurses has been found. We believe that this study may open the way for future studies for the improvement of the working environment by the hospital and healthcare services managers.

\section{Objective}

The aim of this study is to investigate the role conflict and role ambiguity in pediatric nurses who work outside and in the pediatric ICU and whether the situation varies according to some characteristics of the nurses.

\section{MATERIALS and METHODS}

\section{Type of the Study}

This study was conducted in accordance with the descriptive research type. ${ }^{26}$

\section{Place and Time of the Study}

This study was conducted between October I, 2019 and February I, 2020 in in-patient clinics, ICUs with featured units (neonatal, pediatric, pediatric surgery, and cardiovascular surgery $\mathrm{ICU}$ ), and other featured units (emergency, operating room, and burn unit) of a pediatric hospital.

\section{The Target Population and the Sample of the Research}

The target population of the study was composed of nurses working in the hospital $(N=353)$. The sample consisted of nurses who worked in the hospital and met the sampling criteria. The sampling criteria were as follows: to be working in a featured unit or inpatient clinic, being a bedside nurse, and having worked in the unit for at least I month. Total count sampling method was used. The whole target population of the study was included in the sample of the study ${ }^{26}(\mathrm{~N}=295)$, and this study was completed with 210 nurses.

\section{Data Collection Tools}

Nurse Personal Information Form. It was developed based on the literature by researchers to determine the sociodemographic and professional characteristics of nurses. $5,10,12,14,27$ it consists of 17 questions in total.

Role Conflict and Role Ambiguity Scale. The original "Role Conflict and Role Ambiguity Scale" was developed by Rizzo et al. $^{28}$ Later, it was finalized by Schuler et al. ${ }^{29}$ It was first adapted to Turkish by Kaygin ${ }^{30}$ and later by Yildirim, ${ }^{31}$ who provided its face validity. The scale measures the role conflict and role ambiguity that the individuals experience. It consists of 14 items, eight items measure the role conflict and six items measure the role ambiguity. ${ }^{3 l}$ The last eight items in the scale are about role conflict, and the first six items are about role uncertainty. ${ }^{29}$ The scale has been prepared according to the sevenpoint Likert scale ( $\mathrm{I}=$ absolutely wrong and $7=$ absolutely correct). Total points for role conflict and role ambiguity are recorded separately. The minimum total point is 8 and maximum is 56 for role conflict, while the minimum total point is 6 and maximum is 42 for role ambiguity. The high score for role conflict indicates that the conflict is experienced more, whereas the lower score for role ambiguity indicates that the ambiguity is experienced more. The test-retest reliability coefficient of the adapted scale was $0.8 \mathrm{l}$ for role conflict and 0.72 for role ambiguity, and the internal consistency reliability coefficient was determined as 0.82 for role conflict and 0.63 for role ambiguity. ${ }^{31}$ In our study, it was found 0.83 for role conflict and 0.78 for role ambiguity. 


\section{Collection of the Data}

Nurses were provided to fill in the data collection tools by providing the necessary information through individual face-toface interviews by the researchers. In order to contact all nurses, the units were visited at different working hours. Filling the tools took 5-10 minutes for each nurse.

\section{Evaluation of the Data}

The data were analyzed using the Statistical Package for the Social Sciences (SPSS) version 25.0 (IBM SPSS Corp.; Armonk, NY, USA). Descriptive statistics (number, percentage, mean, standard deviation, and median) were used to evaluate the data. The reliability of the scale was tested by reliability analysis. In the scale, role conflict was found in accordance with normal distribution, whereas role ambiguity was not. In comparison of the data, for the scale that showed normal distribution, the independent samples t-test was used in analyzing two groups and one-way analysis of variance for more than two groups, and for the non-normally distributed scale, the Mann-Whitney $U$ test was performed analyzing two groups, and the Kruskal-Wallis analysis was performed for more than two groups. The Bonferroni test was used to find the group that created a difference in the analysis of more than two groups. The level of statistical significance was accepted as $P<.05^{26}$

\section{Ethical Aspect of the Research}

Approval for this study was obtained from the University of Health Sciences Dr. Behcet Uz Child Disease and Pediatric Surgery Training and Research Hospital Clinical Research Ethics Committee (approval date: September 26, 2019; approval number: 2019/|4-|I), hospital management, and Mrs. Yildirim, who adapted the scale. Nurses' consent was obtained using an informed consent form.

\section{RESULTS}

The mean age of the nurses in the hospital was $34.87 \pm 8.30$, $63.8 \%$ of them had an undergraduate degree, and the average years in the profession were $12.59 \pm 8.37$. It was found that the weekly working time in the hospital was $52.74 \pm 9.14$ hours, and those who worked most for 57-72 hours were the ICU nurses, with a rate of $42.1 \%$. The average number of nurses during day shift was $2.17 \pm 0.38$ for ICU and $5.83 \pm 1.62$ for clinic, while during night shift, it was $2.62 \pm 0.80$ for ICU and $9.49 \pm 2.37$ for clinic. The rate of nurses receiving a certificate was the highest among the ICU nurses (30.7\%). Most of the nurses in the hospital had received general (85.2\%) and unit-specific (79.5\%) training in duties, authorities, and responsibilities, and had received orientation training in the hospital (89\%) and the unit (91.9\%) (Table I).

The mean score for role conflict of the nurses in the hospital was $35.74 \pm 9.34$, and the mean score of role ambiguity was $39.90 \pm 5.71$. According to the unit worked in, the mean score for role conflict was $37.38 \pm 9.46$ in the clinic, $36.63 \pm 8.93$ in other featured unit, and $33.80 \pm 9.15$ in the ICU, and the mean score for role ambiguity was $30.05 \pm 5.96$ in other featured unit, $30.48 \pm 5.36$ in the clinic, and $31.68 \pm 5.90$ in the ICU (Table 2). The mean score for role conflict of nurses in the clinic was significantly higher than those in the ICU (F $=3.42, P=.03$ ) (Table 3).

In the analysis of the mean score for role conflict, it was found that the nurses in the hospital with a period of more than 10 years spent in the profession $(37.06 \pm 8.82)$ had significantly higher scores than those who spent less than 5 years (32.2I \pm 10.66) ( $F=3,87, P=.02$ ). Similarly, for the nurses in the ICU, those who had 5 - 10 years $(35.02 \pm 8.22)$ and more than 10 years in the profession $(35.38 \pm 8.26)$ had significantly higher scores compared with those with less than 5 years $(27.94 \pm 10.8 \mathrm{I})(\mathrm{F}=$ $4.70, P=.01)$. For the nurses in other featured units, those who spent more than 10 years in the profession $(40.75 \pm 6.91)$ also had significantly higher scores than those who spent less than 5 years (34.II $\pm \| .77)(F=3.33, P=.04)$. It was observed that the nurses in other featured units who worked for 40 hours weekly (44.50 \pm 6.89$)$ had higher scores compared with those who worked for 4l-56 hours weekly (33.94 \pm 9.21$)(F=3.58, P=$ .03). The mean score for role conflict was significantly higher in the clinic nurses who received certificates $(45.66 \pm 6.74)$ when compared with those who did not $(36.74 \pm 9.37)(t=2.28, P=$ .02). The distribution of the mean role conflict scores varied according to orientation, in such a way that in hospital nurses, those who did not receive a certificate $(39.43 \pm 10.75)$ had significantly higher scores when compared with those who did $(35.29 \pm 9.08)(t=-2.01, P=.04)$. Similarly in ICU nurses, those who did not receive a certificate $(41.00 \pm 7.41)$ had significantly higher scores than those who did $(33.18 \pm 9.06)(\dagger=-2.21, P=$ .02) (Table 4).

In evaluation of the median scores for role ambiguity, it was seen that there was a statistically significant difference only the nurses in other special units had a significant difference in terms of working time spent in the profession, the hospital, and the unit. Those who had more than 10 years of work experience in the profession (26.00) had highly significantly lower scores than those who spent less than 5 years (34.00) and 5 - 10 years (36.00) ( $\mathrm{KW}=9.65, P=.008)$; those who had more than 10 years of work experience in the hospital (26.00) had significantly lower scores than those who had less than 5 years (34.00) ( $\mathrm{KW}=8.64, P=.0 \mathrm{l})$; and those who had more than 10 years of work experience in the unit (26.00) had highly significantly lower scores than those who had less than 5 years (34.00) ( $K W=10.30, P=.006$ ). The median score for role ambiguity was significantly lower in clinic nurses who received a certificate (27.00) when compared with those who did not receive a certificate (31.00) $(U=121.50, P=.05)$. The median score for role ambiguity in nurses in other featured units who received unit-specific training in duties, authorities, and responsibilities (25.50) was significantly lower than those who did not (29.50) $(U=43.00, P=.03)$. The median score for role ambiguity in hospital nurses who did not receive orientation (30.00) was significantly lower when compared with those who did (32.00) $(U=1500.50, P=.01)$ (Table 5).

\section{DISCUSSION}

The ability of pediatric nurses to provide quality care to the child and the family depends on their ability to perform their roles. $^{32}$ The working environment is dynamic and complex since it requires the performance more than one role at a time." Factors such as job-oriented work, inadequate employment, and lack of information about the role negatively affect the nurses in performing their roles. ${ }^{32}$

In this study, it was seen that the role conflict in nurses in the hospital was above the moderate level. Similar results to our study have been achieved in other national studies. ${ }^{14,19,22}$ On the other hand, some studies suggest that the conflict was not 
TABLE I. Mean and Percentage Values of the Sociodemographic and Professional Characteristics of Nurses

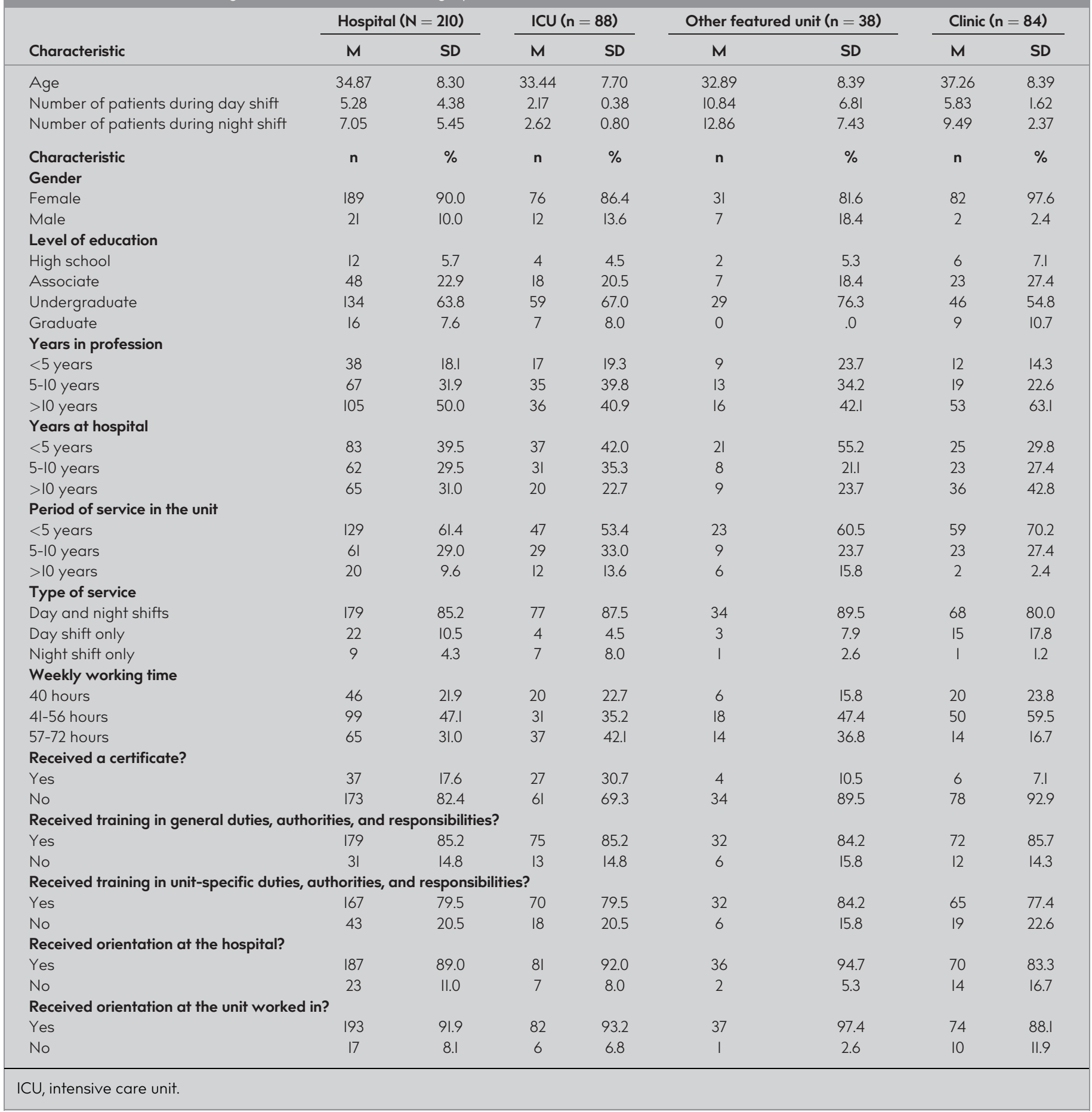

TABLE 2. Mean and Median Scores of the Nurses' Role Conflict and Role Ambiguity

\begin{tabular}{|c|c|c|c|c|c|c|c|c|}
\hline Unit worked in & \multicolumn{4}{|c|}{ Role conflict } & \multicolumn{4}{|c|}{ Role ambiguity } \\
\hline Hospital & 35.74 & 9.34 & 37.00 & $8.00-55.00$ & 39.90 & 5.71 & 32.00 & $10.00-42.00$ \\
\hline Other featured unit & 36.63 & 8.93 & 37.00 & $20.00-53.00$ & 30.05 & 5.96 & 29.00 & $16.00-42.00$ \\
\hline Clinic & 37.38 & 9.46 & 39.00 & $14.00-55.00$ & 30.48 & 5.36 & 30.50 & $17.00-42.00$ \\
\hline
\end{tabular}

$\mathrm{ICU}$, intensive care unit.

*Min-max: minimum-maximum. 
TABLE 3. Comparisons of the Mean Scores for Role Conflict and Median Scores for Role Ambiguity of Nurses According to the Unit They Work in

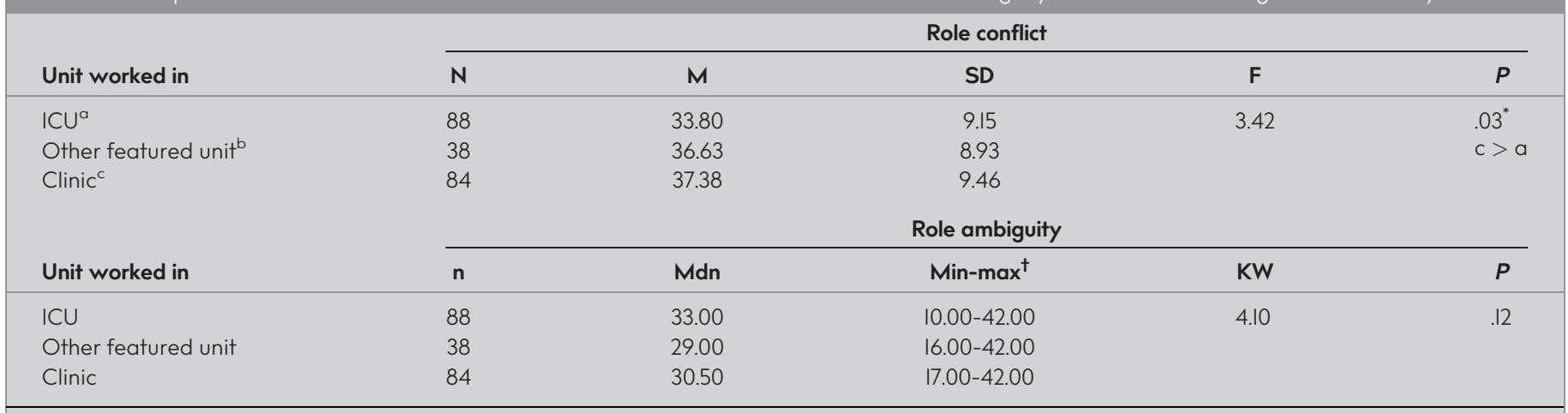

$I C U$, intensive care unit.

${ }^{*} P<.05$.

${ }^{\dagger}$ Min-max: minimum-maximum.

TABLE 4. Comparison of the Mean Scores for Role Conflict According to the Sociodemographic and Professional Characteristics of Nurses

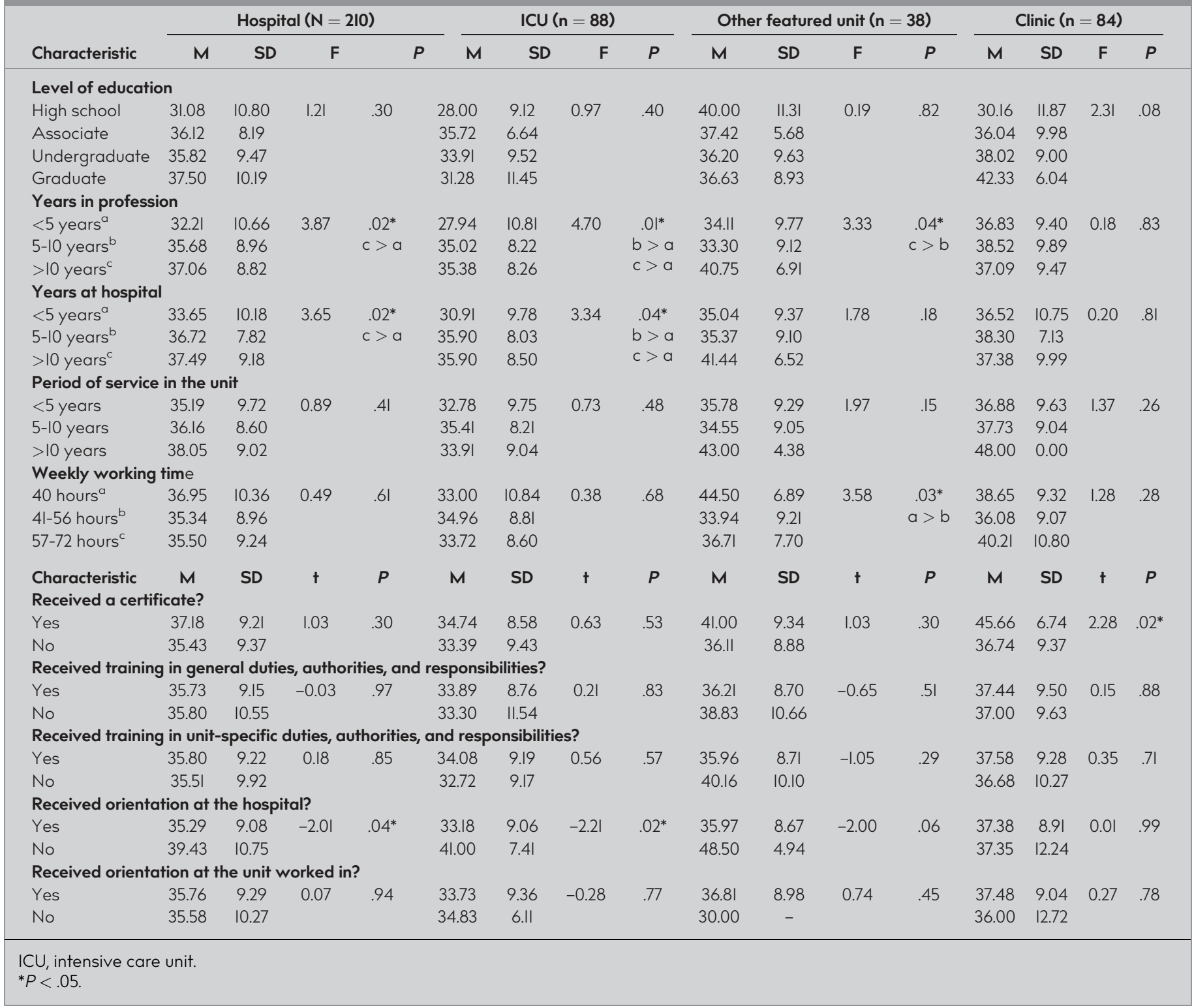


TABLE 5. Comparison of the Median Scores for Role Ambiguity According to the Sociodemographic and Professional Characteristics of Nurses

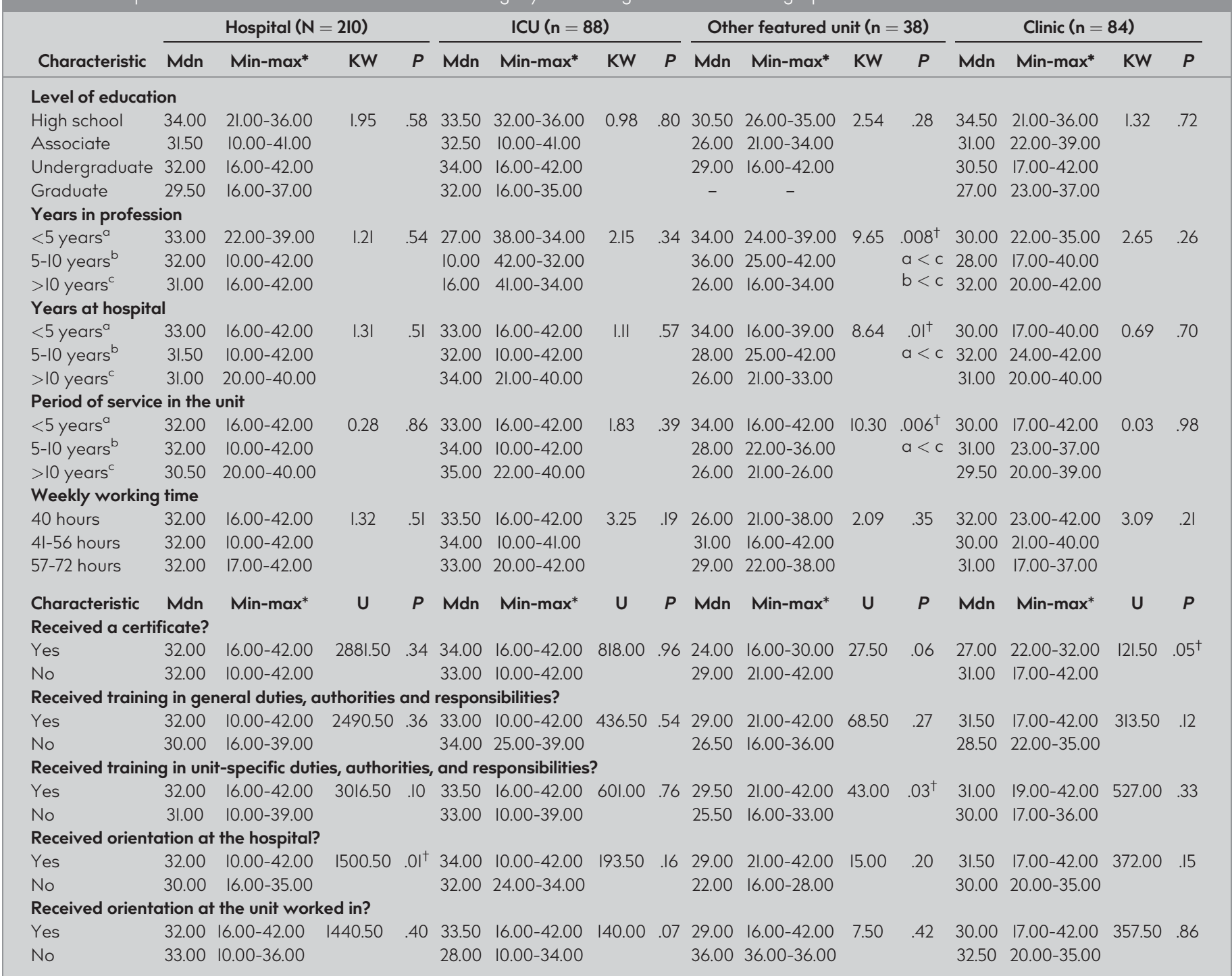

$\mathrm{ICU}$, intensive care unit.

*Min-max: minimum-maximum.

$+p<.05$.

experienced, ${ }^{12}$ was experienced below the moderate level (I5.20), or was experienced at the moderate level. ${ }^{13}$ The results from international studies are also compatible with those of this study. ${ }^{16,17}$ In two studies, it is seen that the conflict is experienced at a moderate level. ${ }^{18,21}$ It is common to experience a role conflict in a profession that plays many roles simultaneously, such as nursing. Within the healthcare team, each member may consider his/her own demand to be more important. Responding to the family's demands while performing the roles of pediatric nurses may have an impact on their role conflict.

It can be stated that the nurses in the hospital have not experienced any role ambiguity. In a study conducted in our country, similar results were reported, ${ }^{12}$ while in other studies, the ambiguity was reported to be below the moderate level, ${ }^{20}$ at the moderate level, ${ }^{13}$ or above the moderate level. ${ }^{14,15,19,22}$ In other countries, findings supporting this study have been reported. ${ }^{17,21}$ However, some other studies showed that it was experienced at a moderate level. ${ }^{16,18}$ This difference between the results of the pediatric nurses and adult nurses may be due to the nature of the pediatric patient. Working in child clinics, the team carries out many initiatives, within or outside its role, taking the best interests of the child into account. Role ambiguity may also result from differences in the institutional structure. It can be said that job descriptions in the hospital are very clear. Considering that most of the nurses in the hospital hold at least an undergraduate degree (7l.4\%), it can be stated that nurses with higher education levels are more aware of their roles.

It is seen that the nurses in the clinic experienced more role conflicts than those in the ICU. In another study, it was found that the nurses in surgical clinics lived longer than those in the $\mathrm{ICU}$, operating room, and emergency room. ${ }^{27}$ In contrast, other studies reported that those in the ICU experienced more conflict $^{10}$ at a moderate level. ${ }^{5}$ Pediatric intensive care nurse is the person who coordinates the team for the care of critically ill and highly vulnerable children. ${ }^{25}$ In this study, it can be said that a team work was adopted in ICU, expectations from the intensive care nurse were compatible, and that the nurse did not have to choose between the roles despite the stressful 
environment. The fact that the lowest percentage of holding an undergraduate degree was among the clinic nurses (54.8\%) can be considered as a cause. A stable, permanent, and competent nursing workforce in the ICU improves patient outcomes. ${ }^{25}$ The fact that the ICU nurses had the highest percentage in having a certificate and the clinic nurses had the lowest may have caused this result. The average number of patients in the ICU during day shift (2.17) and night shift (2.62) is considered to be standard, which indicates that their workloads are normal. On the other hand, it can be asserted that the difference in the number of patients between day and night shifts in the clinic caused this result.

We found that the role ambiguity score of the nurses did not change according to the unit they worked in. The findings of other studies are not in line with ours; the scores were higher ${ }^{10}$ and above the moderate level. ${ }^{5}$ The result of this study can be explained by the institutional arrangements and pediatric nurses' full comprehension of their duties, authorities, and responsibilities depending on their professional characteristics. Accountability, responsibility, and autonomy are required to improve patient outcomes in the intensive care environment. ${ }^{5}$ We also observed that the nurses working in the ICU experienced the least role ambiguity. Relocation of the interrelated personnel in the institution is among the causes of role ambiguity. ${ }^{14}$ Half of the nurses in the ICU have been working here for at least 5 years.

Role conflict and role ambiguity results of the nurses were different based on some of their characteristics. We found that this difference was not based on the nurses' educational background. The same result was obtained for role conflict ${ }^{27}$ in one study and for role ambiguity in another. ${ }^{15}$ In another study, those with an undergraduate degree experienced more role conflict than high school graduate. ${ }^{14}$ While it is expected that the nurses with a higher level of educational would experience it less, the actual result can be explained by the average period of 12.59 years spent in the profession. In addition, it seems that this may be caused by the fact that the majority of the nurses have received training in duties, authorities, and responsibilities and orientation.

The process of gaining professional competence has been defined by Benner in five stages, namely, the "Novice to Expert" model: novice, advanced beginner, competent, proficient, and expert. The expert stage requires graduate and certified training with at least 5 years of experience and includes intuitive decision making based on knowledge and experience that does not require rules. ${ }^{33}$ The role conflict in the nurses in hospitals, ICUs, and other featured units increases as the working time increases. In two studies, the exact opposite results of this study were obtained, ${ }^{12,27}$ while in another study, there was no difference. ${ }^{14}$ Role ambiguity in nurses in other featured units increases as the time spent in the profession increases. In other studies, however, it did not change. ${ }^{12,14}$ This unexpected finding may be attributed to the fact that the graduate education $(7.6 \%)$ and the certified education (17.6\%) required by the expert stage are not sufficient. It is stated that nurses spend 30 $40 \%$ of their time on jobs other than care, which are their main roles. ${ }^{10}$ In comparison to the clinic, the weekly working time was higher and working in the night shifts was more in the hospital, ICU, and other featured units, which shows that the workload was also higher. From another point of view, this result can be explained by the decision-making feature of the expert stage that is not limited by the rules. Also, the concept of autonomy can be mentioned. Professional autonomy is to make its own decisions about own practices, and it emphasizes independent nursing roles.' It can be said that pediatric nurses possess professional autonomy.

Clinic nurses who own a certificate experience more role conflicts and role ambiguities than those who do not. This unexpected result can be explained by the fact that, in this group, the percentage of high school graduates (7.1\%) and the percentage of those who worked in the unit for a period of less than 5 years $(70.2 \%)$ was the highest, whereas the percentages of those who received orientation training from the hospital and from the unit worked were the lowest.

Role ambiguity was higher in nurses in other featured units who were not trained in unit-specific duties, authorities, and responsibilities. This result emphasizes the importance of clearly defining the responsibilities and limits of the nurse in featured units such as emergency, operating room, and burn unit, which are special branches of nursing that have its own special structure and functioning.

Newly started nurses have difficulty in integrating their professional roles with the institution's expectations regarding their roles. $^{34}$ At this point, orientation training helps these nurses acquire the necessary knowledge and skills. ${ }^{35}$ Role conflict in the hospital and ICU nurses, and role ambiguity in the hospital nurses are more commonly observed in those who have not received orientation training from the hospital. It can be thought that an orientation training given on the hospital basis clarifies nursing roles.

\section{Conclusion and Suggestions}

We demonstrated that nurses in the hospital experienced role conflict above the moderate level; however, they experienced no role ambiguity. We found that nurses in the clinic experienced more role conflicts than those in the ICU. Hospital, ICU, or other featured unit nurses who spent more years in the profession; hospital and ICU nurses who spent more years in the hospital; nurses in other featured units who had a low total of weekly working time; clinic nurses who received a certificate; and hospital and ICU nurses who have not received orientation training from the hospital experienced more role conflicts. Other featured unit nurses who spent more years in the profession, the hospital, and the unit; clinic nurses who received a certificate; other featured unit nurses who have not received unitspecific training in duties, authorities, and responsibilities; and hospital nurses who have not received orientation training from the hospital experienced more role ambiguity.

The working environments in health institutions create a favorable ground for role conflict and role ambiguity. Developing strategies suitable for the institution in order to reduce role conflict and role ambiguity by executive nurses is recommended. For this purpose, a system where nurses can communicate their problems can be used to determine the root causes. Encouraging graduate and certificate education can yield results. This issue can be addressed in in-service training and orientation training programs organized at the institution or unit level for the newcomers. During the adaptation period, counselor nurses can be used. It is important to address this issue during nursing education before graduation in order to train nurses who are capable of responding to incompatible role expectations and 
are aware of what their job is about. Conducting studies comparing pediatric and adult nurses, and revealing the nurses' perceptions and experiences about their roles with qualitative studies are recommended.

\section{Limitations of the Research}

This study had some limitations. The first one concerns the measuring tool. Scale scorings were performed differently in different studies. In this study, the study about the adapted scale was taken as the basis. It is important to take this situation into account when interpreting the findings and planning researches in the future.

The generalizability of the findings is limited due to the fact that our study was a single-center study. This study was conducted in a training and research hospital of a public university. Therefore, the results may not be generalized to all hospitals. Since the sample consisted of pediatric nurses, the results may not represent all nurses.

Ethics Committee Approval: Ethics committee approval was received for this study from the University of Health Sciences Dr. Behcet Uz Child Disease and Pediatric Surgery Training and Research Hospital Clinical Research Ethics Committee (approval date: September 26, 2019; approval number: $2019 / 14-11)$.

Informed Consent: Written informed consent was obtained from nurses who participated in this study.

Author Contributions: Concept - D.Ş., M.Ü.Ç.; Design - D.Ş., M.Ü.Ç.; Supervision - D.Ş.; Resource - D.Ş., M.Ü.Ç., N.I., N.Y; Materials - D.Ş., M.Ü.Ç; Data Collection and/or Processing - M.Ü.Ç., N.I., N.T.; Analysis and/or Interpretation - D.Ş., M.Ü.Ç., N.I., N.T.; Literature Search - D.Ş., M.Ü.Ç., N.I., N.T.; Writing - D.Ş., M.Ü.Ç., N.I., N.T.; Critical Review - D.Ş.

Conflict of Interest: The authors have no conflicts of interest to declare.

Financial Disclosure: The authors declared that this study has received no financial support.

\section{REFERENCES}

I. Taylan S, Alan S, Kadioglu S. Roles of nursing and autonomy. J Res Dev Nurs. 2012;2:66-74.

2. R.T. Official Gazette. Law amending the nursing law. May 2, 2007. Number: 26510 .

3. R.T. Official Gazette. Regulation amending the nursing regulation. April 19, 20II. Number: 27910.

4. Weiss SA, Tappen RM, Grimley KA (eds.). Work-related stress and burnout. In Essentials of Nursing Leadership and Management. 7th ed. Philadelphia: F.A. Davis, 2019:121-138.

5. Iliopoulou KK, While AE. Professional autonomy and job satisfaction: Survey of critical care nurses in mainland Greece. J Adv Nurs. 2010;66(II):2520-253I. [CrossRef]

6. Scholes J (ed.). New roles in critical care practice. Developing Expertise in Critical Care Nursing. Oxford: Blackwell, 2006:179-206.

7. Almost J, Wolff AC, Stewart-Pyne A, Mccormick LG, Strachan D, D'Souza C. Managing and mitigating conflict in healthcare teams: An integrative review. J Adv Nurs. 2016;72(7):1490-1505. [CrossRef]

8. Uyer G, Abaan S. Organizational communication. In Uyer G, Kocaman G (eds.): Nursing Services Management Handbook. Istanbul: Koc University, 2016:327-348.

9. Manojlovich M. Nurse/physician communication through a sensemaking lens, shifting the paradigm to improve patient safety. Med Care. 2010;48(II):941-946. [CrossRef]
10. Dasgupta P. Effect of role ambiguity, conflict and overload in private hospitals' nurses' burnout and mediation through self efficacy. J Health Manag. 2012;14(4):513-534. [CrossRef]

II. Kim WS, Nicotera AM, McNulty J. Nurses' perceptions of conflict as constructive or destructive. J Adv Nurs. 2015;71(9):2073-2083. [CrossRef]

12. Akbulut Basci AB, Ozyurda F, Yilmazel G. The level of work related tension and role conflict-role ambiguity status of nurses working in Ankara University Hospitals. J Acad Res Nurs. 2016;2(2):51-58. [CrossRef]

13. Adiguzel $\mathrm{O}$. The impact of work related stress, role clash and role ambiguity on employee turnover: An application on nurses. Int $J$ Alanya Fac Busi. 2012;4(3):163-169.

14. Akbolat M, Isik O, Ugurluoglu O. Comparison of locus of control, job satisfaction, role ambiguity and role conflict of health employees. Hacettepe Univ J Econ Adm Sci. 2011;29(2):23-48. [CrossRef]

15. Bal Tastan S. The theoretical implications of job demandsresources model: A research study on the relations of job demands, supervisor support and job autonomy with work engagement. Atatürk Univ J Econ Adm Sci. 2014;28(4):I49-192. [CrossRef]

16. Han SS, Han JW, An YS, Lim SH. Effects of role stress on nurses' turnover intentions: The mediating effects of organizational commitment and burnout. Jpn J Nurs Sci. 2015;12:287-296. [CrossRef]

17. Iyer RD, Deshmukh M. Moderating effect of workplace spirituality on role stressor and job satisfaction among Indian nurses. J Manag Public Policy. 2018;9(2):15-30. [CrossRef]

18. Kaihlanen AM, Elovainio M, Haavisto E, Salminen L, Sinervo T. Final clinical practicum, transition experience and turnover intentions among newly graduated nurses: A cross sectional study. Nurs Educ Today. 2020;84:I-9.

19. Ozbozkurt OB, Ozbozkurt N. The mediating role of job satisfaction within the impact of role ambiguity and role conflict on job performance: A research on operating private hospitals in Mersin. Anemon J Soc Sci Mus Alparslan Univ. 2019;7(4):307-314.

20. Polatci S, Ozyer K. A research about the effect of role stressors on burnout. J Acad Soc Sci Stud. 2015;33:29-40.

21. Roelen CAM, Van Hoffen MFA, Waage S, et al. Psychosocial work environment and mental health-related long-term sickness absence among nurses. Int Arch Occup Environ Health. 2018;91:195203. [CrossRef]

22. Tunc T, Kutanis RO. Role conflict, role ambiguity, and burnout in nurses and physicians at a university hospital in Turkey. Nurs Health Sci. 2009;II(4):4I0-4l6. [CrossRef]

23. Dare Azeez F. Role ambiguity and organizational justice as the predictors of unethical behavior among nurses. J Client-Centered Nurs Care. 2019;5(2):81-86. [CrossRef]

24. Roch G, Dubois CA, Clarke SP. Organizational climate and hospital nurses' caring practices: A mixed-methods study. Res Nurs Health. 2014;37(3):229-240. [CrossRef]

25. Moloney Harmon PA, Curley MAQ. The nurse in pediatric critical care. In Fuhrman BP, Zimmerman JJ (eds.): Pediatric Critical Care. 4th ed. Philadelphia: Mosby, 20Il:23-30.

26. Erdogan S, Nahcivan N, Esin N (eds.). Research in Nursing: Process, Implementation and Critical. Ist ed. Istanbul: Nobel Medicine, 2014.

27. Kara Sivuk D, Kibris S. Role conflict and role ambiguity in health institutions: A research on nurses. J Prod. 2016;4:33-50.

28. Rizzo JR, House RJ, Lirtzman SI. Role conflict and ambiguity in complex organizations. Adm Sci Q. 1970;15(2):150-163. [CrossRef]

29. Schuler RS, Aldag RJ, Brief AP. Role conflict and ambiguity: A scale analysis. Organ Behav Hum Perform. 1977;20(I):III-128. [CrossRef]

30. Kaygin EG. Work-Related Attitudes of Staff in Hospitals, Staff Turnover, Ankara Province Example [dissertation]. Hacettepe University, Graduate School of Health Sciences, 1994. 
31. Yildirim F. Relationship Between Job Satisfaction and Perceived Role Conflict and Burnout in Bank Employees [master's thesis]. Hacettepe University, Graduate School of Social Sciences, 1996.

32. Hizel Bahceci M, Celebioglu A. Impact of a refresher training on pediatric nurses' realization of their roles and functions. $J$ Pediatr Res. 2017;4(3):130-136. [CrossRef]
33. Karahan A, Kav S. Professional competency in nursing. J Hacettepe Univ Fac Nurs. 2018;5(2):76-84. [CrossRef]

34. Sabanciogullari S, Dogan S. Professional identity development and nursing. J Anatolia Nurs Health Sci. 2012;15(4):275-282.

35. Ulupinar Alici S, Cakir A. Nurses' opinions about clinical orientation period practiced in a private hospital. Maltepe Univ J Nurs Sci Art. 2009;2(I):I-12. 